\title{
María Zambrano. Filósofa de la generación del 27
}

\section{María Zambrano. Philosopher of the Generation of ‘27}

Reseña de: Zacarés Pamblanco, A. y Mascarell Dauder, R. [2021]. María Zambrano. Filósofa de la Generación del 27. Madrid: Ediciones Antígona.

ISBN: 978-84-18119-46-0, 176 págs.

JOSÉ BELTRÁN LLAVADOR

Universitat de València Jose.Beltran@uv.es ORCID ID: http:/ / orcid.org/0000-0003-1065-3032

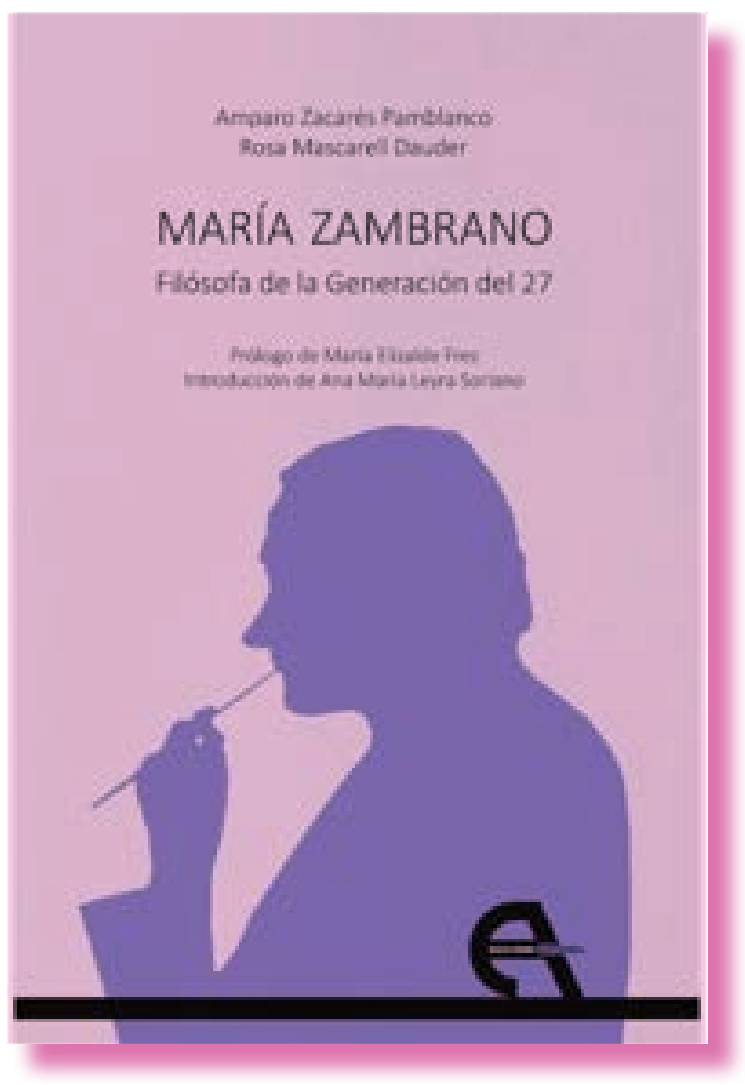

Mientras redacto este texto, Amparo Zacarés y Rosa Mascarell, están presentando el 7 de diciembre su libro María Zambrano. Filósofa de la Generación del 27, recién publicado, en la Università Tor Vergata de Roma. Es un acto organizado por el International Research Center of Aesthetic and Art Theory [IRCA] y por el Instituto Cervantes [que las autoras visitarán dos días después]. 


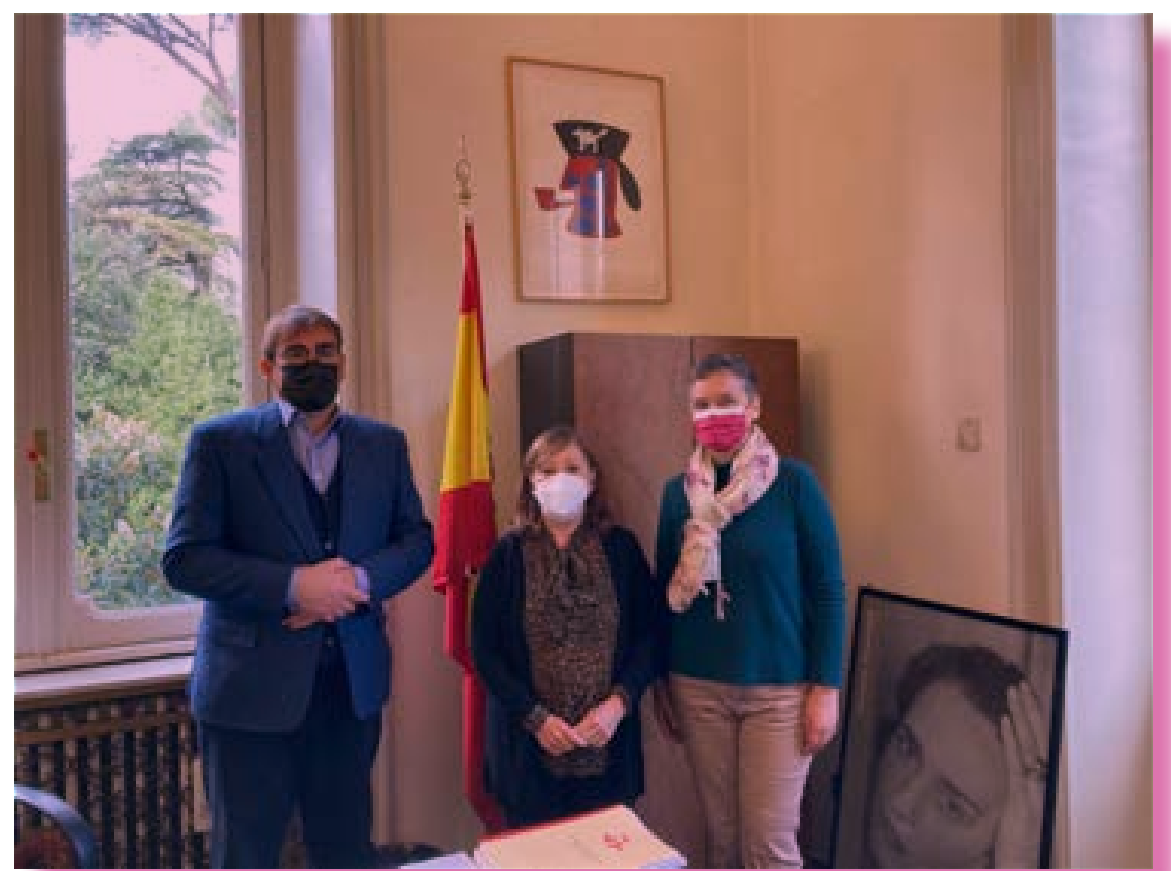

Fig. 1. El director del Instituto Cervantes de Roma, Juan Carlos Reche, con Amparo Zacarés y Rosa Mascarell.

En esta presentación también participa Laura Mariateresa Durante, profesora de la Università di Napoli Federico II, difusora y traductora de María Zambrano al italiano. La introducción y coordinación corre a cargo de Giuseppe Patella, buen amigo desde hace años de Amparo Zacarés por sus conexiones en estudios en torno a Giambattista Vico y de quien firma esta reseña por sus intereses comunes sobre George Santayana.

Un mes antes, el martes 2 de noviembre, las dos autoras habían realizado una presentación de su libro en el Centro Cultural de la Generación del 27 en Málaga. En un breve mensaje Amparo nos decía que esta presentación "tuvo el valor simbólico de reivindicar y visibilizar no solo a la filosofía sino también a todas las mujeres artistas y poetas de aquella generación que fueron borradas de la historia de la cultura de nuestro país."

Anticipando esta publicación, el 14 de mayo de 2020, la periodista alemana Rilo Chmielorz compuso y firmó su reportaje sobre María Zambrano a partir de la entrevista realizada a Rosa Mascarell y a Amparo Zacarés para el programa Perspektiven de la Radio Kultur de Berlin. En la banda sonora de este reportaje sonaban las notas de los cuatro libros de la "Música callada" que Federico Mompou compuso entre 1959 y 1967. La elección de esta pieza no es casual, sino que acompaña de la mejor manera los escritos de la pensadora y aquellos que se inspiran en su obra, como el libro que nos ocupa. Ahora mismo suenan en mi estudio, variaciones sobre la serie, las

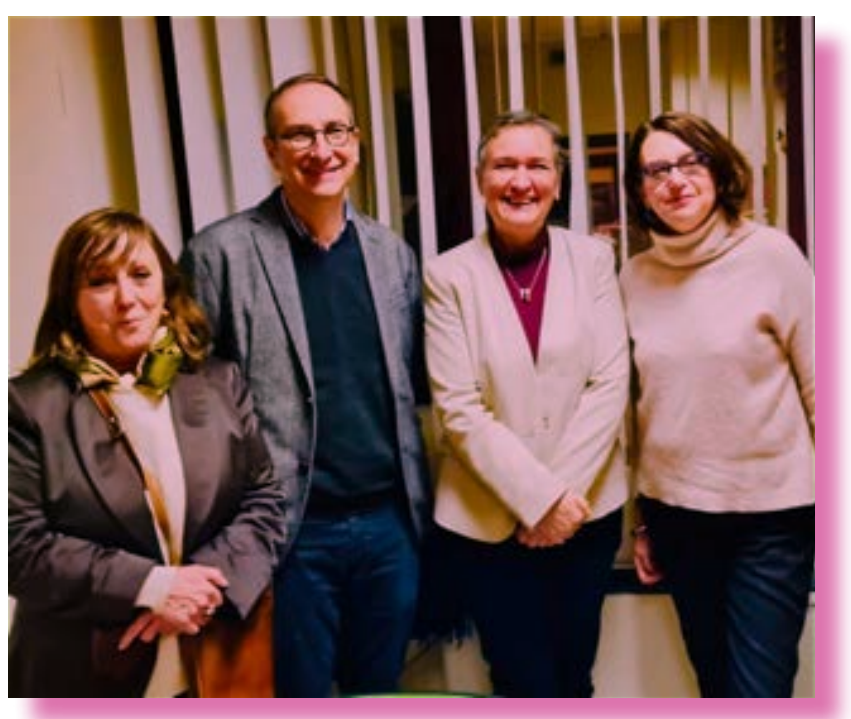

Fig. 2. Amparo Zacarés, Giuseppe Patella, Rosa Mascarell y Laura Mariateresa Durante 
mismas piezas interpretadas por el propio Mompou (en 1974, en el Casino de I'Aliança del Poblenou], por Herbert Henck en 1995, por Arcadi Volodos en 2013 [en cuyo libreto Adolf Pla compara la música de Mompou a la arquitectura de Antonio Gaudí y a la filosofía y poesía de María Zambrano], y por Luis Aracama en 2018.

Amparo ya me había hablado de esta iniciativa, hace algunos años, cuando apenas era una idea, pero una idea que encerraba una clara determinación. Se trataba de abrir un diálogo, junto a Rosa Mascarell, en torno a la pensadora, con un doble propósito: por una parte, restituir su pensamiento a su lugar de pertenencia dentro de esa deslumbrante

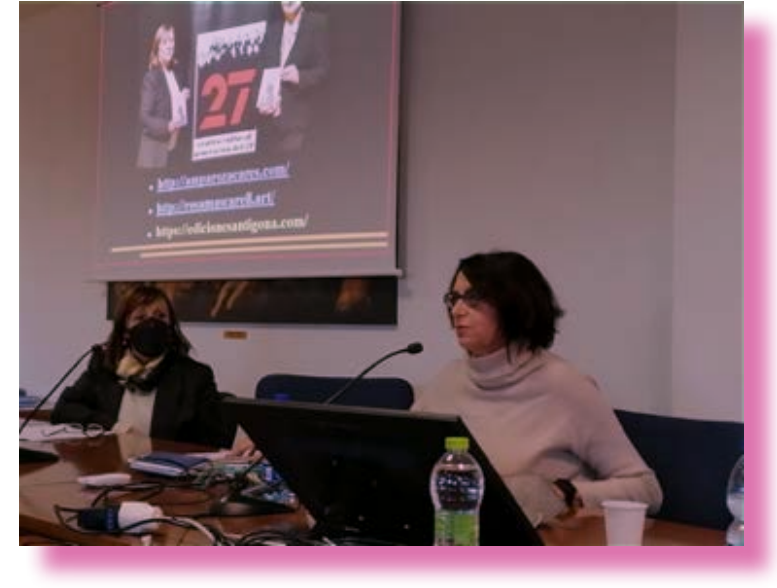

Fig. 3. Amparo Zacarés y Laura Mariateresa Durante aludiendo a la presentación en el Centro Cultural de la Generación del 27. constelación que constituyó la Generación del 27; y por otra parte, vindicar una razón poética como forma de pensar, expresar y encarnar el mundo. De modo que este libro también se puede interpretar como un manifiesto, una protesta de serenidad, que muestra el valor de la poesía como herramienta de conocimiento, tendiendo puentes entre racionalidad y sensibilidad. No es poca cosa en tiempos donde el primado del algoritmo y la hegemonía positivista acaban velando la presencia de lo humano, nunca demasiado humano, y de sus aspiraciones "hacia un saber sobre el alma".

Que Amparo Zacarés y Rosa Mascarell hayan decidido compartir este proyecto acerca y en compañía de María Zambrano no es fruto de la casualidad, pero tampoco de la causalidad. Forma parte de esas encrucijadas -esos cruces de caminos- que van apareciendo haciendo camino al andar. No hay más que asomarse a las páginas web de las dos autoras para ver las conexiones y "resonancias" [en término de Hartmut Rosa) entre ambas. La nota biográfica que aparece en la página de Amparo Zacarés [https://amparozacares.com/] apenas hace justicia a una trayectoria académica tan vital y plural que quizá podría resumir el concepto spinozista de conatus. Algo similar sucede cuando uno se asoma a la página de Rosa Mascarell [http://rosamascarell.art/autora/] y descubre la variedad de perspectivas en la que se viene desplegando sus quehaceres culturales y artísticos, entre los que resalta, sin duda, el hecho de haber conocido de primera mano a María Zambrano, como secretaria y documentalista durante sus últimos años en España. Pero en obras como la que nos ocupa queda claro que Rosa Mascarell no sólo administró el legado intelectual de María Zambrano, y que Amparo Zacarés no sólo leyó con atención y tesón sus libros, sino que ambas participaron -y siguen haciéndolo- del amor mundi que se desprende de su obra.

En esta ocasión, María Zambrano. Filósofa de la Generación del 27 cuenta con un prólogo de María Elizalde Frez, sin duda, una de las mayores expertas en la obra de la pensadora malagueña. La introducción, a cargo de Ana María Leyra Soriano, directora de la revista Escritura e imagen, dimensiona muy bien la filosofía española en el ámbito de la estética, "reflexión sobre la tarea creadora, análisis del modo en que los conceptos se manifiestan vinculados a la vida."

Las intenciones de este libro quedan expuestas en las primeras páginas, en estas se dan cita dos efemérides que sirven de homenaje a la filósofa poeta: los ochenta años cumplidos en 2019 de la edición de Filosofía y Poesía, durante su exilio en México, por la Universidad Michoacana, 
y el treinta aniversario de su fallecimiento en 2021. María Zambrano alumbró en Morelia - "la bella Morelia", en sus propias palabras - el libro fundacional que le abrió las puerta a los lugares de la razón poética, allí donde se encuentran el logos y el pathos, el pensar y el padecer. Tuve ocasión de visitar Morelia en una estancia académica en 2005. Ahora pienso que quizá el trazado cartesiano y en forma de cuadrícula de sus calles en contraste con la imaginería desbordante de sus tradiciones y el barroquismo de sus iglesias pudo influirle en esa conjunción de reflexión y creación, de carnalidad y espiritualidad: dejarse respirar por la vida e inspirarse en la vida vivida.

En los anaqueles de mi estudio he ido atesorando algunos títulos de la escritora-pensadora, que han ido ampliando el horizonte de mis lecturas más obligatoriamente "ortodoxas". Las páginas de María Zambrano me han permitido participar de una exploración -una forma de meditaciónhacia el despertar de la palabra. En esa exploración no cuentan las búsquedas sino los hallazgos. Heráclito escribió: "Si no esperas lo inesperado, no lo encontrarás." Esos encuentros que nos regalan los textos de la pensadora no admiten planificaciones, cálculos ni atajos: aparcen como revelaciones en sendas perdidas, de tan ocultas casi secretas; las rutas que nos llevan a esos "claros del bosque" se han liberado de la recta opinión, son rodeos y merodeos, son incursiones en lo indecible.

Estos días se puede visitar en Valencia una exposición dedicada al contraste -similitudes y diferencias - entre Oteiza y Chillida. Chillida también tradujo en lenguaje plástico la "música callada" [en la exposición de 1994] de Juan de la Cruz, como Mompou hicera en lenguaje sonoro, una figura que atraviesa buena parte de la obra de María Zambrano y a cuya firma presta atención en Los bienaventurados. Una de las obras de Chillida lleva por título "Rumor de límites". Es una metáfora muy expresiva de la prosa poética que va tejiendo María Zambrano en tantos libros a los que he podido asomarme y que vienen a buscarme ocasionalmente: Los sueños y el tiempo, La tumba de Antígona, Delirio y destino, Notas de un método, La agonía de Europa, El hombre y lo divino, Hacia un saber sobre el alma, Claros del bosque, De la Aurora, La confesión: género literario, los tres poemas rescatados por Jesús Moreno [El ángel del límite y el confín intermedio], La España de Galdós, la correspondencia con Ramón Gaya y María Zambrano [ $Y$ así nos entendimos...], la antología La razón en la sombra... Todos ellos proporcionan una soledad sonora, un rumor de límites. Todos ellos constituyen un "elogio del horizonte" trenzado de voces antiguas, evocadoras, que rememoran un origen insondable al tiempo que conjuran señales del futuro.

Lo que han hecho Amparo Zacarés y Rosa Mascarell es muy meritorio, pues no se han propuesto hacer un ensayo sobre María Zambrano, sino que han entrado en diálogo con su obra. Y lo han hecho, además, siguiendo su magisterio, more María Zambrano, esto es, desde la razón poética y desde los lugares privilegiados de la pintura. Es este, pues, un libro de diálogos. No solo dialogan con la pensadora poeta, sino que las autoras dialogan entre sí, y para ello se han puesto de acuerdo para ordenar sus intervenciones. Han generado un universo vocabular a partir de seis palabras -clave de bóveda- generadoras de significados: método, naufragio, delirio, memoria, luz, poesía. Abre el pórtico a cada palabra, como un paisaje al que asomarnos, una ilustración y un escrito de Rosa Mascarell, y a continuación Amparo Zacarés elabora una digresión alrededor de cada palabra clave. La elección de estas palabras no ha sido azarosa, ha formado parte del viaje filosófico que han emprendido. Estas seis palabras dibujan un cosmos, cada una de ellas encierra un pequeño tratado de perplejidades, y todas nos invitan a participar de la conversación que mantienen entre sí.

Método apela a la vía de conocimiento, que no es meramente intelectual, sino material y experiencial. Somos materia encarnada: cuerpo y corpus, texto y textura, sentido y sensibilidad. 
Aprendemos de la memoria (del recuerdo, de cor, cordis: en inglés es muy clara la relación directa entre memoria y corazón: learning by heart). Nuestro pensar es una forma de vivir, una forma de vida, que también es parte de la alquimia de la vida. Amparo Zacarés impugna el relato platónico que escinde en nuestro mundo el plano sensible del plano inteligible, y que condena de manera despiadada a los poetas al exilio, como si la poesía no fuera una manera de pensar y de participar en la creación de nuestro mundo. Qué bien lo expresa Rosa Mascarell en su pintura, cuando identifica método con constelación: Método es la vía [el camino] láctea [de la luz]. Ese anhelo de luz, reflejado en el oro alquímico, que transforma la bóveda de la noche en una danza de iluminaciones.

Naufragio: Esa pintura con pétalos que no acaban de sumergirse en las aguas del exilio, que flotan, que sobreviven, como ha explicado Rosa Mascarell en su presentación en Roma. Ese pétalo que fue María Zambrano captada en una hermosa fotografía en la playa de la Malvarrosa en 1937 con el grupo de actores y actrices de La Barraca, cuando Valencia era la capital de La República, un sueño truncado por la Guerra Civil y convertido en pesadilla. Naufragar es tomar conciencia de la necesidad de un logos poético para sobreponerse a un destino no elegido.

Delirio: Abre el pórtico de la palabra una composición de Rosa Mascarell introduciendo en la tabla, además de oro fino, cuerda. Y quiero pensar que son surcos en la tierra. La cita que escoge de Delirio y destino para su breve texto, lleno de sugerencias, ya desmiente el significado al uso de la palabra delirio que la identifica con locura: “¿Por qué no ha de contener una autobiografía verdadera delirios que no son una falacia de falso ensoñamiento?" No una patología, sino una forma de lucidez, una atención consciente. Y dice Ramón Andrés, en Pensar y no caer, en ese capítulo que no tiene desperdicio titulado "La escritura, la tierra", en el que vincula la actividad de leer con el cometido de ciertas actividades agrícolas, entre ellas, la recolección: "La lectura es, por supuesto, una recolección. Y no parece menos indicativo que los campesinos de los dominios de Roma, una vez terminado el tiempo de barbecho, y decididos de nuevo a roturar, llamaran Lira [lira] -no lyra, como el instrumento musical- al surco con el cual empezaban a despertar el campo y que, en ocasiones, señalaba el límite del terreno. Quien no podía llevar adecuadamente la atadura, quien no acertaba a labrar ese surco con destreza o, peor aún, se salía de su recto trazo, de-liraba. Delirio." (p. 143). María Zambrano se empeñó en delirar, se propuso "plantar" cara a la orto-doxia. Decimos, como nos recuerda también Ramón Andrés: "Pensar es escribir, es sembrar", o bien: "Leer es cultivarse". [p. 144]. María Zambrano se dedicó a recolectar y a sembrar, a cultivar y cultivarse en el terreno de lo real, "algo que está pasando siempre y no puede dejar de pasar." Pero para sentir ese proceso -señala Amparo Zacarés- "hay que adentrarse en el vértigo del instante que lo ilumina todo y en el delirio inacabable de la vida que muere y nace de nuevo." [p. 84].

Memoria: La representación plástica de la memoria es, para Rosa Mascarell, una suerte de espejo bruñido de oro fino, un espacio en el que ad-mirar-se, re-cordar-se y re-conocer-se. No es transparente: está velado y nos invita a des-velarlo para encontrar lo inesperado. La memoria requiere estar en vela, desvelados. Los surcos de la memoria -que también cultivamos- nos adentran en laberintos de sentido. La poesía es el hilo de Ariadna para alcanzar la salida del laberinto, es el hilo de oro previo a la filosofía que nos transporta a lugares anteriores al nacimiento de la filosofía. Poesía, como sugería Giambattista Vico y señala Amparo Zacarés, que proviene del cuerpo y de la imaginación. En Notas para un método, María Zambrano descifra un enigma: el poeta "olvida lo que el filósofo recuerda y es la memoria misma de lo que el filósofo olvida." La 
memoria es el lugar por encontrar - la utopía [u-topo]- de la vita nova. El lugar en el universo al que aspira la razón poética.

Luz. La luz de María Zambrano es una confesión y una vocación. La cita elegida por Rosa Mascarell para invitarnos a la palabra luz es una declaración de intenciones: "He preferido la penumbra salvadora que andar errante, sola, perdida, en los ínferos de la luz", dice la pensadora en Filosofía y Poesía. Y la pintura de Rosa Mascarell dialoga con esta luz de María Zambrano, mostrándonos de nuevo una gradación de tonos que puede verse como esa luz que declina -crepúsculo- en el oro de la tarde y que se convierte en penumbra, o como esa luz que surge al alba como un nacimiento, como un alumbramiento. Ambas son luces tenues, luces que se tejen y destejen entre sombras, que dejan entrever, pero no deslumbran. No son las luces de la razón, sin más, son las luces de la razón poética. No son luces que describen notarialmente la realidad, sino que la reescriben y la recrean poéticamente. Son esos claros del bosque que alivian nuestra errancia, esos claroscuros de Zurbarán [como ha recordado Giuseppe Patella en el seminario], o ese aire que respira en los cuadros de Velázquez, al que Ramón Gaya llamó "pájaro solitario", o las mismas flores y bautismos de Ramón Gaya, el buen amigo de María Zambrano. Esa luz que María Zambrano descubrió en "algunos lugares de la pintura", tan elocuente en su silencio. Se podría decir que todo el proyecto de María Zambrano está sembrado de noticias de la luz por venir: es una anticipación, es una anunciación.

Si este libro es una vindicación de la razón poética, la palabra poesía tiene la última palabra. De nuevo Rosa Mascarell traduce en pintura callada la palabra poesía con una tabla alimentada de oro fino y cuerda. Apenas dos insinuaciones en forma de círculos sobre un fondo oscuro que nos interrogan. Como todo buen cuadro nos está solicitando, nos está llamando: quisiera conversar contigo. Así también la poesía, esa voz antigua que de forma metódica nos ayuda a rememorar el primer naufragio del que procedemos, esa creación que prende y sorprende porque nos da [I] a luz con metáforas poderosas, ese anhelo de sabiduría, ese modo de rebeldía, esa praxis de la esperanza, la filosofía encarnada como una experiencia vital. En definitiva, la mejor expresión del amor mundi, como nos recuerda Amparo Zacarés en su última entrega.

He tenido la fortuna de poder asistir [a distancia) al seminario dedicado a este libro en Roma. Allí también estaban presentes Sertório Amorim y Silva Neto, Giorgia Moretti, Ana López Rico, Carlotta Urriani, Daniela Masciandaro, Elisa Ragnoni, Alina Gabriella Stan, Giovanni Bruni, Luca Lamberti, Marta Pandolfi, Mirko Fattore, Rosario Riso, Sara Ciancarelli, Francesco dell Isola. Roma fue muy importante para María Zambrano, y no pocas de sus obras se han traducido al italiano. Por eso, si la presentación de este libro en Málaga fue muy importante para restituir definitivamente a María Zambrano como filósofa de la Generación del 27, en la edad de plata de la cultura española; la presentación en Roma le da una dimensión simbólica especial, porque la voz de María Zambrano alcanza de esta manera -en el ámbito universitario romano [donde todos los caminos se encuentran]- una proyección universal. La generación del 27 creó una utopía, afirmó en el seminario Laura Mariateresa Durante. Una utopía es el lugar de la esperanza. "Es la esperanza - dice María Zambrano en el último texto de Los bienaventurados- que crea suspendida sobre la realidad sin desconocerla, la que hace surgir la realidad aún no habida, la palabra no dicha: la esperanza reveladora; nace de la conjunción de todos los pasos señalados, afinados y concertados al extremo; nace del sacrificio que nada espera de inmediato más que sabe gozosamente de su cierto, sobrepasado, cumplimiento." 
Fig. 4. Cartel de la Presentación del libro en Roma (Italia] el 7 de diciembre de 2021.

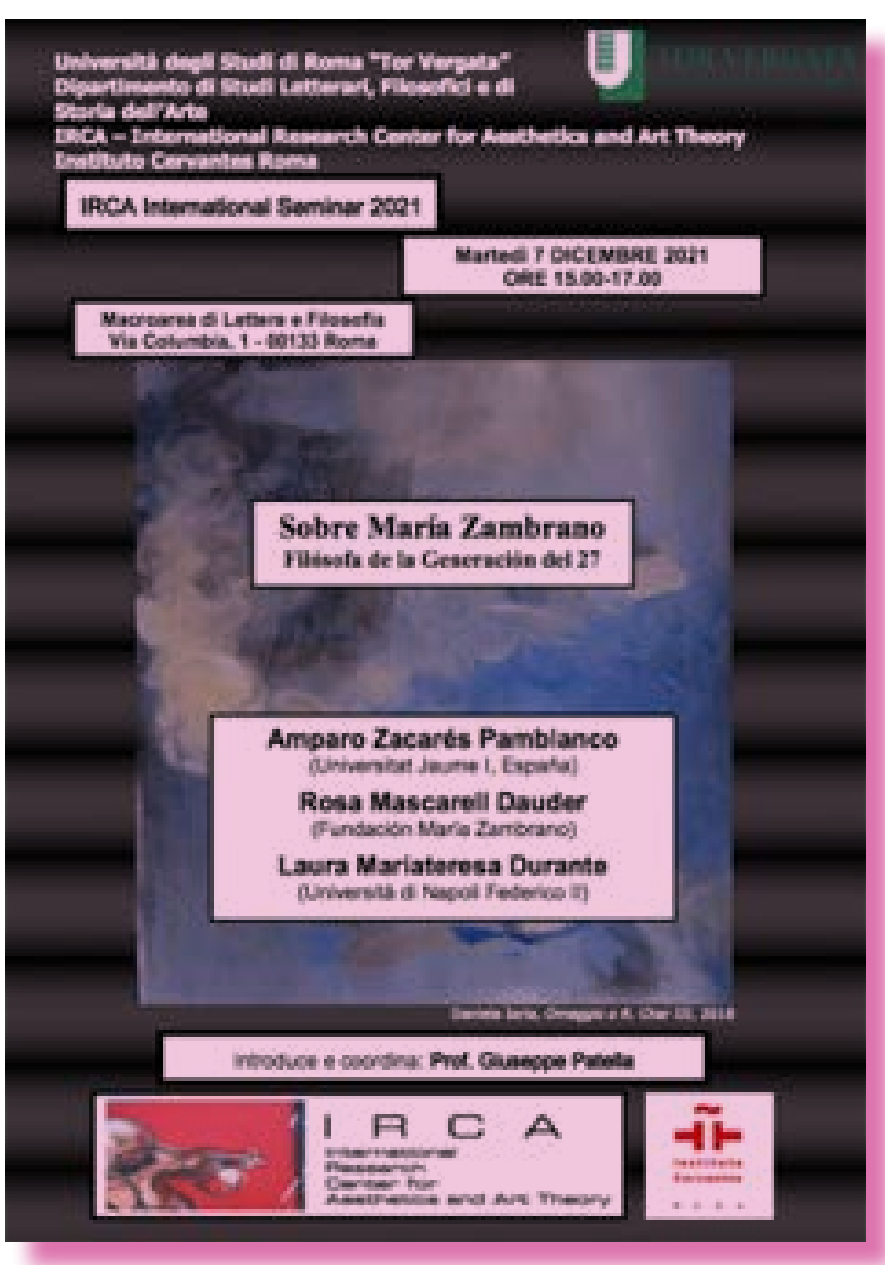

Los textos que componen este libro de Amparo Zacarés y Rosa Mascarell, en compañía de María Zambrano, son un merecido y oportuno homenaje a una inigualable maestra, librepensadora, filósofa poeta. Sus lectores [recolectores] podemos sentirnos afortunados. En estas páginas, sembradas de esperanza, se encuentran tantas lecciones valiosas como sugerentes inspiraciones. En estos tiempos sacudidos por vientos de doctrina, leer esta obra es atreverse a soñar despiertos, ser poéticamente razonables y a la vez rebeldes, y participar en la aventura de hacer del amor a la sabiduría una forma de vida. 